Acta Hispanica (2016) 21: 7-9

\title{
DISCURSO DEL DR. MIHÁLY SZAJBÉLY
}

Sabíamos desde hacía meses que tenía una enfermedad grave. Sabíamos desde hacía meses que había pocas esperanzas. A pesar de todo, seguíamos mostrándonos optimistas.

Hace exactamente 50 años, en 1966 fue licenciado en Historia y Filología Húngara por la Universidad Attila József de Szeged, institución predecesora de nuestra universidad. Cincuenta años después de finalizar sus estudios, la Facultad de Filosofía y Letras les otorga a sus antiguos estudiantes un diploma con mención honorífica, un diploma de oro. Lo estábamos esperando también a él para la ceremonia de entrega de diplomas, celebrada este año el 24 de septiembre, una hermosa mañana de sábado otoñal, en el Auditorio Máximo de la Universidad. Habría querido participar, esperaba poder participar en este evento, pero no llegó a presenciarlo. Fue entonces, durante los preparativos de la celebración, cuando me enteré de su enfermedad, de la gravedad de su enfermedad.

Después esperamos, yo también. Todo ha terminado. Nos queda la despedida, en este preciso momento de adviento, a la luz de las velas, y nos quedan los recuerdos, queda la conmemoración.

Nuestros encuentros muy frecuentes delante del edificio de la Facultad de Filosofía y Letras, cuando acababa de bajar del coche, o iba hacia su coche, iba y venía entre los dos edificios. Aunque nos encontrábamos a menudo, siempre nos parábamos para compartir algunas palabras. Lo respetaba y lo quería. Una vez salió del coche, se le cayó la llave de la mano, y desapareció entre las rejas del alcantarillado. Nos pusimos de rodillas, la sacamos de alguna manera, y así, a cuatro patas, nos miramos y nos echamos a reír. En aquel entonces, él ya era profesor, pero eso no le importaba, su sentido del humor no lo abandonó ni en esta situación extraordinaria.

Otro recuerdo, de 15-20 años antes, de los principios de los años 1980: yo todavía era profesor ayudante, $y$, junto con otros docentes jóvenes, presentamos una propuesta de reforma para renovar la formación de filólogos, a la cual le pusimos, con cierta ironía, el título de Intención inocente. Y no sin razón, no conseguimos mucho con esta propuesta. Pero Ádám lo recordó, y cuando fue nombrado vicedecano en 1985, nos mandó a Pécs, a la Facultad de Filosofía y Letras recién fundada, para ver cómo se hacía allí el examen de ingreso. Ya que allí, en la universidad recién creada a partir de la escuela superior, en muchos terrenos se actuaba con más agilidad que en nuestra universidad, y Ádám Anderle quería renovar la rutina de aquí también. Nos consideraba sus aliados, intentaba ponernos en buena posición, nos ayudaba.

Porque siempre estaba dispuesto a echar una mano, si se encargaba de algo, se lo tomaba muy en serio. Fue en 1995 cuando se publicó la novela del escritor austríaco, Erich Hackl titulada Sara und Simon, cuya trama tiene lugar en los tiempos de la dictadura militar en Uruguay, y que tuvo mucho éxito en el mundo alemán. Hice la traducción al húngaro para la Editorial Magvető (Magvető Kiadó), pero antes de mandarles el manuscrito, le pregunté a Ádam si lo leería, y cuál era su opinión 
profesional. No solo lo leyó, sino también lo revisó como lector-redactor. Acepté todas sus sugerencias, la única cosa en la que no pudimos llegar a un acuerdo fue el dilema de si se suele 'portar' o 'portear' a los bebés.

Era un hombre de horizontes amplios, una persona de asiento, era sereno, prudente. Si decía algo, todos le prestaban atención. Siempre podíamos contar con él también cuando ya era profesor emérito, lo echaremos de menos, y mucho, en el Consejo de Profesores de la Facultad. Era respetado, y también por aquellos que no estaban de acuerdo con él.

Es incuestionable lo que ha llevado a cabo en el terreno de la ciencia, de la coordinación de las investigaciones y de la formación de las futuras generaciones de científicos. Makai László escribió así sobre su maestro, el profesor Tibor Wittman:

"Por más paradójico que nos parezca, es verdad que reconocer las relaciones universales de la historia mundial es indispensable para los historiadores de las naciones pequeñas, porque, mientras los historiadores de las grandes naciones tienden a generalizar las características de su propia historia nacional como principios de validez universal, los historiadores de las naciones pequeñas se ven obligados a considerar la historia de su propia nación como parte o, incluso, consecuencia de la historia universal. [..] Esta consideración fue lo que dirigió el interés de Tibor Wittman hacia más allá de las fronteras de Hungría y, más tarde, de Europa.”

Las palabras de László Makai fueron citadas por Ádám Anderle en su gran estudio en el que presentó y valoró la carrera de Tibor Wittman, y yo las cito ahora porque pienso que lo mismo ha caracterizado al profesor Anderle. Tras la muerte temprana de Tibor Wittman, muchos pensarían que se acababa todo lo que él había intentado realizar aquí, en Szeged. Ádám Anderle desmintió a los escépticos, y no solo siguió, sino que también culminó el legado de su maestro. Por un lado, continuó tejiendo la red de las relaciones internacionales que había creado Wittman, por otro lado, en 1982, fundó el Grupo de Investigación de la Historia de América Latina. Este grupo cosechó tanto éxito que, 10 años más tarde, en 1993, en sus bases pudo nacer el actual Departamento de Estudios Hispánicos.

Toda esta labor que llevaba a cabo en la coordinación_institucional y científica era garantizada por la actividad científica cada vez más completa de Ádám Anderle. Sus casi 300 publicaciones científicas -libros, fragmentos de libros, artículos en revistas en lengua húngara o extranjera, sobre todo, en español, de los cuales era autor o editorsobre la historiografía de América Latina, sobre la historia de la emigración húngara a América Latina, sobre cuestiones de las relaciones húngaro-españolas en los siglos XIXXX hicieron que su nombre fuera conocido en Hungría, en el mundo hispano e, incluso, más allá de este. Sus obras forman parte de los textos esenciales frecuentemente citados de la disciplina.

Sobresalió también en el terreno de la formación de las futuras generaciones de científicos: 20 de sus discípulos han obtenido el título de doctor. 
El último libro de Ádám Anderle, una colección de estudios bajo el título Spanyol mozaik (Mosaico español), se publicó el pasado noviembre por la editorial Kronosz. El autor pudo tenerlo en su mano todavía antes de su fallecimiento. Consideremos esto como una gracia de la suerte y de la intención editorial. Este tomo, subtitulado Tanulmányok a hispanista kutatások történetéböl (Estudios de la historia de las investigaciones hispanistas), contiene también el mencionado estudio sobre la carrera del profesor Tibor Wittman, una apreciación profesional precisa a base de criterios histórico-científicos, en el fondo de la cual, sin embargo, se percibe el respeto, el amor y el aprecio al antiguo maestro. Consideremos también gracia de la suerte que la labor de Tibor Wittman en crear una escuela en Szeged tuviera un seguidor y culminador como el profesor Ádám Anderle. La evaluación sumaria y la apreciación de su carrera, con el paso del tiempo, cuando se vaya aliviando el dolor, será tarea de sus discípulos.

Descanse en paz, nuestro querido colega, compañero y amigo, profesor Ádám Anderle.

Traducido por Veronika Praefort 